\title{
Integrative Review of the Nursing Interventions Used for the Early Detection of Cervical Uterine Cancer
}

\author{
Camila Teixeira Moreira Vasconcelos ${ }^{1}$ \\ Marta Maria Coelho Damasceno ${ }^{2}$ \\ Francisca Elisângela Teixeira Lima ${ }^{3}$ \\ Ana Karina Bezerra Pinheiro ${ }^{4}$
}

In a national program to combat cervical uterine cancer (CUC) four basic elements should exist: primary prevention, early detection, diagnosis/treatment and palliative care. Of these, early detection is the most effective modality. One of the purposes of EvidenceBased Practice (EBP) is to encourage the use of research results with the assistance provided, reinforcing the importance of research for clinical practice. This study aimed to evaluate the evidence available in the literature regarding effective nursing interventions for the early detection of CUC. The selection of articles was performed in the databases: Scopus, PubMed, CINAHL, Lilacs and Cochrane. The sample of this review consisted of seven articles, with evidence levels 1,2 or 3 . The behavioral, cognitive and social interventions, showed positive effects in the early detection of CUC, especially the interactive cognitive interventions. It is suggested, when appropriate, to use a combination of interventions in order to obtain a more effective result.

Descriptors: Nursing; Women's Health; Uterine Cervical Neoplasms; Vaginal Smears; Evidence-Based Nursing.

\footnotetext{
${ }^{1}$ RN, Doctoral student in Nursing, Universidade Federal do Ceará, Fortaleza, CE, Brazil. Scholarship holder of Coordenação de Aperfeiçoamento de Pessoal de Nível Superior (CAPES). E-mail: camilamoreiravasco@hotmail.com.

2 RN, Professor, Departamento de Enfermagem, Universidade Federal do Ceará, Fortaleza, CE, Brazil. E-mail: martadamasceno@terra.com.br.

${ }^{3}$ RN, Ph.D. in Nursing, Professor, Departamento de Enfermagem, Universidade Federal do Ceará, Fortaleza, CE, Brazil. E-mail: felisangela@yahoo.com.br.

${ }^{4}$ RN, Professor, Departamento de Enfermagem, Universidade Federal do Ceará, Fortaleza, CE, Brazil. E-mail: anakarinaufc@hotmail.com.
}

Corresponding Author:

Ana Karina Bezerra Pinheiro

Universidade Federal do Ceará. Departamento de Enfermagem

Rua Alexandre Baraúna, 1115

Bairro: Rodolfo Teófilo

CEP: 60430-160 Fortaleza, CE, Brasil

E-mail: anakarinaufc@hotmail.com 


\title{
Revisão integrativa das intervenções de enfermagem utilizadas para detecção precoce do câncer cérvico-uterino
}

Em um programa nacional de combate ao câncer cérvico-uterino (CCU) devem existir quatro elementos básicos: prevenção primária, detecção precoce, diagnóstico/tratamento e cuidados paliativos. Desses, a detecção precoce é a modalidade mais efetiva. Um dos propósitos da Prática Baseada em Evidências é encorajar a utilização de resultados de pesquisa junto à assistência prestada, reforçando a importância da pesquisa para a prática clínica. Esse estudo objetivou avaliar as evidências disponíveis na literatura sobre as intervenções de enfermagem eficazes na deteç̧ão precoce do CCU. A seleção dos artigos foi realizada nas bases: Scopus, PubMed, CINAHL, LILACS e Cochrane. A amostra desta revisão constitui-se de 7 artigos, com níveis de evidência 1, 2 ou 3 . Tanto as intervenções comportamentais como as cognitivas e sociais mostraram efeitos positivos na detecção precoce do $\mathrm{CCU}$, com destaque para as intervenções cognitivas interativas. Sugere-se, quando adequado, utilizar combinação das intervenções para se obter resultado mais eficaz.

Descritores: Enfermagem; Saúde da Mulher; Neoplasias do Colo Uterino; Esfregaço Vaginal; Enfermagem Baseada em Evidências.

\section{Revisión integradora de las intervenciones de enfermería utilizadas para detección precoz del cáncer cervicouterino}

\begin{abstract}
En un programa nacional de combate al cáncer cervicouterino (CCU) deben existir cuatro elementos básicos: prevención primaria, detección precoz, diagnóstico/tratamiento y cuidados paliativos. De estos, la detección precoz es la modalidad más efectiva. Uno de los propósitos de la Práctica Basada en Evidencias es incentivar la utilización de resultados de investigación junto a la asistencia prestada, reforzando la importancia de la investigación para la práctica clínica. Este estudio objetivó evaluar las evidencias disponibles en la literatura sobre las intervenciones de enfermería eficaces en la detección precoz del CCU. La selección de los artículos fue realizada en las bases: Scopus, Pubmed, CINAHL, LILACS y Cochrane. La muestra de esta revisión se constituye de 7 artículos, con niveles de evidencia 1, 2 o 3. Tanto las intervenciones comportamentales, como las cognitivas y sociales mostraron efectos positivos en la detección precoz del CCU, con destaque para las intervenciones cognitivas interactivas. Se sugiere, cuando adecuado, utilizar una combinación de las intervenciones para obtener un resultado más eficaz.
\end{abstract}

Descriptores: Enfermería; Salud de la Mujer; Neoplasias del Cuello Uterino; Frotis Vaginal; Enfermería Basada en la Evidencias.

\section{Introduction}

Cervical uterine cancer (CUC) is a global disease, despite presenting the greatest potential for prevention and cure (nearly $100 \%$ ) when diagnosed early. It is the second most common cancer among the female population, accounting for over 250,000 deaths in 2005 , with $80 \%$ of these deaths occurred in developing countries $^{(1)}$. Rates of CUC have decreased over the last thirty years in most developed countries, probably as a result of screening and treatment programs. Conversely, these rates have increased or remained unchanged in most developing countries. It is noteworthy that there are also inequalities in the developed world, where women from rural or poor areas are at greater risk of facing the invasive type of CUC(1).

By presenting a slow evolution, with a long period from the development of precursor lesions to the onset of cancer, various actions can be performed in order to break the epidemiological chain of the disease ${ }^{(2)}$. In a 
national program to combat CUC there should be four basic elements: primary prevention, early detection, diagnosis/treatment and palliative care ${ }^{(1)}$. Early detection is the most effective modality in reducing this disease ${ }^{(3)}$. Early detection includes systematic screening programs aimed at the appropriate age groups, with effective links between all levels of care, as well as the education of health professionals and women, highlighting the benefits of the screening examination in the age groups that typically manifests this cancer, its signs and symptoms.

Several studies have evaluated the role of the nurse in the prevention and control of CUC as critical due to the diverse areas of work of this professional with women and due to the use of educational strategies ${ }^{(4-5)}$. Nurses are constantly challenged in the pursuit of knowledge in order to promote the improvement of nursing care ${ }^{(6)}$. One of the purposes of Evidence-Based Practice (EBP) is to encourage the use of research results with the assistance provided in the different levels of healthcare, reinforcing the importance of research for clinical practice(7). The integrative literature review is one of the research methods used in EBP, which allows the incorporation of evidence into the clinical practice. This method aims to gather and synthesize research findings on a determined theme or question, in a systematic and orderly manner, contributing to a deepening of knowledge on the subject investigated ${ }^{(7)}$.

To guide the integrative review, the following question was formulated: which nursing interventions are effective in the early detection of CUC? In order to contribute to the improvement of nursing care in the fight against CUC, this study aimed to evaluate the evidence available in the literature regarding effective interventions for the early detection of CUC.

\section{Methodological procedure}

For the elaboration of this integrative review, the following steps were covered: establishment of the hypothesis and aims of the integrative review; establishment of criteria for inclusion and exclusion of articles (sample selection); definition of the information to be extracted from the selected articles; analysis of the results; discussion and presentation of the results; with the final step constituted by the presentation of the review ${ }^{(7)}$. For the selection of articles the following databases were used: LILACS (Latin American and Caribbean Health Sciences Literature), PubMed (Public/ Publisher Medline), CINAHL (Cumulative Index to Nursing and Allied Health Literature), SCOPUS and COCHRANE.

Initially, the criteria defined for inclusion of articles in this integrative review were: to be a complete research article, available electronically, published in Portuguese, English or Spanish; to portray interventions used in the early detection of CUC with at least one nurse on the list of the authors and to have an evidence level of 1 , 2 or 3 . Because of the specific access characteristics of each of the five selected databases, the strategies used to locate the articles were adapted for each, and were guided by the question and the inclusion criteria previously established to maintain consistency in the search for the articles and to avoid possible biases. The following controlled descriptors were used as keywords: 'neoplasias do colo uterino and enfermagem' and 'uterine cervical neoplasms and nursing'. The search was conducted through online access, in October 2009, with the final sample of this integrative review consisting of 07 articles (Table 1 ).

Table 1 - Selection of the research articles in the databases LILACS, PubMed, CINAHL, Scopus and Cochrane according to the established inclusion criteria

\begin{tabular}{|c|c|c|c|c|c|c|}
\hline & Lilacs & PubMed & Cinahl & Scopus & Cochrane & Total \\
\hline Productions found & 02 & 418 & 02 & 178 & 08 & 608 \\
\hline Did not address the thematic of the study & 01 & 300 & 02 & 129 & 03 & 435 \\
\hline Repeated & - & - & - & 38 & 03 & 41 \\
\hline Did not contain intervention & - & 25 & - & 10 & - & 35 \\
\hline Did not have nurses on the list of authors & - & 06 & - & 01 & - & 07 \\
\hline Not available electronically & - & 72 & - & - & 01 & 73 \\
\hline Not a research paper & 01 & 07 & - & - & - & 08 \\
\hline Did not have evidence level 1,2 or 3 & - & 02 & - & - & - & \\
\hline Total selected & 00 & 06 & 00 & 00 & 01 & 07 \\
\hline
\end{tabular}

For data collection, an adapted instrument was used $^{(8)}$, which included the following items: identification of the original article, methodological characteristics of the study, evaluation of methodological rigor, of the interventions and of the measured results. For the analysis and subsequent synthesis of the articles that met the inclusion criteria an adapted synoptic table was used ${ }^{(8)}$, specially constructed for this purpose, which included the following aspects: name of the study, names of the authors, intervention studied, results, recommendations 
and conclusions. After analysis, the interventions were categorized, according to a classification system previously developed, into: behavioral, cognitive or social(9).

Behavioral interventions are those that propose stimuli associated with the realization of early detection examinations for CUC (e.g. reminders). Cognitive interventions are those that provide new information, educate women about the screening examinations and clarify possible misconceptions. Social interventions use peer counselors (members of the community trained to offer information) or professionals in order to increase the examination adherence ${ }^{(9)}$.

The articles were classified as evidence level 1 when the evidence came from a systematic review or meta-analysis of all relevant randomized controlled clinical trials of clinical guidelines based on systematic reviews of randomized controlled clinical trials; 2 if the evidence was derived from at least one well designed randomized controlled clinical trial; and 3 when the evidence was obtained from well designed clinical trials without randomization ${ }^{(10)}$. The presentation of the results and discussion of the data obtained was carried out in a descriptive way, enabling the reader to evaluate the applicability of the elaborated integrative review, in order to achieve the goal of this method.

\section{Results}

Of the selected articles, all were published in journals of international origin. Regarding the databases, six articles were identified in PubMed and one in Cochrane. Concerning the type of journal in which they were published, only one belonged to a medical journal, three were published in general nursing journals and three in nursing journals of specific areas (gynecology and oncology). Regarding the methodological design, the articles were classified as: systematic review $(n=01)$, randomized controlled clinical trials $(n=03)$, clinical trials without randomization $(n=03)$. Of the seven selected articles, there were 24 different types of interventions, 20 had the patients as their target; one, the professionals; and three, changes in the existing system. In general, a greater number of interventions $(n=13)$ used cognitive strategies, followed by behavioral $(n=06)$ and social $(n=04)$ (Table 2$)$.

Table 2 - Characteristics of the studies

\begin{tabular}{|c|c|c|c|}
\hline Intervention & $\mathbf{N}$ & $\%$ & References $^{*}$ \\
\hline Studies & 07 & 100.0 & \\
\hline \multicolumn{4}{|l|}{ Evidence level of the Studies } \\
\hline Level 1 & 01 & 14.0 & 11 \\
\hline Level 2 & 03 & 43.0 & $12,13,14$ \\
\hline Level 3 & 03 & 43.0 & $15,16,17$ \\
\hline Interventions & 24 & 100.0 & \\
\hline \multicolumn{4}{|l|}{ Target of the Intervention } \\
\hline Patients & 20 & 83.3 & $11^{\dagger}, 12,13,14,15,17$ \\
\hline Professionals & 01 & 4.2 & 16 \\
\hline System & 03 & 13.5 & 11,12 \\
\hline \multicolumn{4}{|l|}{ Type of Intervention } \\
\hline Behavioral & 07 & 30.4 & $11,16,17$ \\
\hline Cognitive & 13 & 54.1 & $11,13,14,17$ \\
\hline Social & 04 & 16.5 & $11,12,15$ \\
\hline \multicolumn{4}{|l|}{ Contents of the intervention } \\
\hline Behavioral Intervention & 07 & 100.0 & \\
\hline Reminder letter & 01 & 14.2 & 11 \\
\hline Telephone reminder & 01 & 14.2 & 11 \\
\hline Diagrammatic reminder & 01 & 14.2 & 16 \\
\hline Financial incentives $\ddagger$ & 03 & 43.2 & 11,17 \\
\hline Follow-up protocol & 01 & 14.2 & 11 \\
\hline Cognitive Intervention & 13 & 100.0 & \\
\hline Educational pamphlet or letter & 06 & 46.0 & 11,13 e 17 \\
\hline Counseling by telephone or in person & 02 & 15.5 & 11 \\
\hline Discussion groups & 02 & 15.5 & 14,17 \\
\hline Educational medias (radio, TV, video, slides, newspaper) & 03 & 23.0 & $11,14,17$ \\
\hline Social Intervention & 04 & 100.0 & \\
\hline Care with nurse & 02 & 50.0 & 12,15 \\
\hline Computer use & 01 & 25.0 & 12 \\
\hline Screening system & 01 & 25.0 & 11 \\
\hline
\end{tabular}

* Some studies contain more than one intervention.

${ }^{+}$The systematic review consisted of eight studies and a total of 13 interventions.

* Financial incentives cited were: money for transportation and free Papanicolau examination. 
Various strategies to effectively carry out early detection of CUC, in each related category of intervention, were evaluated.

\section{Behavioral interventions}

Behavioral intervention that used reminders (letters or calls) as their strategy have proved effective in relation to early detection of CUC, whether by increasing examination adherence or by increasing the number of follow-up appointments of women with abnormal examination results. These interventions are based on the assumption that people need only one stimulus (reminder) to practice adequate behavior. For women, this stimulus can be provided through telephone calls or reminder letters to stimulate the performance of the examination or the follow-up appointment(11). In the case of the professionals, diagrammatic reminders are generally used in the patients' medical records or on the admission form, so that they carry out the screening and reinforce the importance of performing the examination at that moment(12). One of the strategies studied was the idealization of a new hospital admission form, with a diagrammatic reminder, containing questions on the screening for CUC, aiming to investigate its effects on two results: the frequency with which the nurse in charge of admissions records information related to the screening and the report of the patients regarding the performance of the examination 4 months after discharge. There was only $01(2.2 \%)$ medical record in the control group (CG) which had a registration of screening, while in the intervention group (IG) there were $29(69 \%)$ registrations $(p=0.001)$. Of the 42 women in the IG, 22 were contacted by telephone 4 months after hospital discharge, of these, 19 (86.4\%) reported not having conducted the examination in that period. Sixteen women reported that the nurse had not talked about the examination during the hospitalization(12). In the same study(12), approximately half of the nurses said there was not sufficient time to discuss screening during the hospitalization, although most agree that the hospital is an important space for discussion of preventive measures. This study demonstrated that the intervention was effective in improving the CUC screening records, however, it did not improve the concern of the women for the performance of the exam. Interventions with the use of protocols for monitoring and financial incentives, such as free examinations or money for transport, significantly improved the adherence to the examination, especially in economically disadvantaged women ${ }^{(11,13)}$.

\section{Cognitive Interventions}

The strategy of sending letters or educational pamphlets, with simple language addressing aspects related to the early detection examinations, had a positive impact on women's knowledge, although this did not always mean an improvement in this practice of the examination ${ }^{(11,13-14)}$. In order to evaluate the effects on the levels of knowledge and anxiety of women with colposcopy scheduled because of an altered cytologic examination, an educational pamphlet containing information about the colposcopic examination was mailed to them. No difference was found between the CG $(50.8 \%)$ and IG (47.9\%) in relation to the level of anxiety $(p>0.05)$. Conversely, after the educational intervention, it was shown that $72 \%$ of the women of the IG had correct comprehension regarding colposcopy, compared to $42 \%$ in the CG $(p<0.05)^{(14)}$.

In another study, which also used the strategy of the educational pamphlet, the women had a statistically superior evaluation of knowledge related to the examination when compared to the others $(p=0.002)^{(13)}$. The use of an educational brochure to motivate women with cytological alterations to carry out the follow-up examination obtained a slight increase in adherence ${ }^{(15)}$. However, when associated with the implementation of a screening system, there was a considerable increase ${ }^{(16)}$. Telephone counseling, conducted to identify and eliminate educational, psychological and practical barriers in relation to the Papanicolau examination, was shown to be an excellent strategy to improve adherence to the examination, even when compared to the telephone reminder(11). Educational sessions, with group discussions, were shown to improve the women's knowledge about the examination, as well as positively influencing them in relation to the intention of performing $i t^{(13,17)}$. One of the interventions tested was a program of cognitive-emotional intervention in the decision of Korean women to take the examination, designed to provide information about the examination and to work on the emotional aspects, such as embarrassment, shyness and anxiety that permeate the performance of this. The results verified that knowledge scores were significantly higher in IG $(p=0.000)$ and that there were differences in the perception of the women regarding the benefits of performing the examination ( $G>C G: p=0.045$ ). There was no difference between the two groups regarding the perception of the susceptibility of women to CUC or regarding the consequences of this pathology. The IG had higher levels of self-efficacy and stronger intentions 
to perform the examination in the near future ${ }^{(17)}$. In another study, women who participated in the educational session also obtained higher percentages of knowledge in relation to the examination $(p=0.000)^{(13)}$.

\section{Social interventions}

The social interventions outlined suggest the use of specific professionals ${ }^{(18-19)}$, such as the health promotion nurse, or changes in the existing care system ${ }^{(11,18)}$, in order to improve the quality of care in relation to CUC screening. In a study carried out in inner London, two types of intervention were tested: computer use and the presence of the health promotion nurse in the team regarding their effects in the care process through the computer records of preventive activities, among them the Pap smear tests performed in the last three years and the smoking history of women. All groups used the computer to record the risk factors, however, the IG had their risk factors checked and monitored by a team composed of the health promotion nurse and the general physician, while the CG was accompanied only by the team composed of physicians ${ }^{(18)}$. Also in this study ${ }^{(18)}$, there was a statistically significant differences in the smoking-related records, in the past five years (IG: $73 \%$ and CG: $57 \%$ ), and in relation to the Pap smear test performed in the last three years in nonhysterectomized women (IG: $76 \%$ and CG: $49 \%$ ). The $24 \%$ increase in registrations of risk factors can be attributed to the intervention used. These data suggest that with organization and resources, over $90 \%$ of the records and monitoring of risk factors can be realized in the practice, even under the most adverse conditions of the rural cities, and that nurses, with defined responsibilities for preventive care in adults, are the key characteristic for such procedures. The computer was a prerequisite for change, however, it was not sufficient to achieve high levels of registration and monitoring, as shown by the CG.

In order to increase the adherence of Chinese women in Hong Kong, the experience and perception of these women regarding the implementation of the Pap smear test with a physician (CG) and with a nurse (IG) were evaluated. Each group was comprised of 50 women randomly assigned and evaluated in relation to the following aspects: technical quality of care, trust in the professional, and quality of the samples collected. Although there was no difference between the overall means of the groups in relation to the first aspect, there was, however, a difference in one individual item related to the information given about the procedure
(IG>CG: $p=0.0130$ ). With regard to confidence in the professional, there was a difference between the groups (IG>CG: $p=0.024)$. There was no statistically significant difference in the overall mean of the item quality of the sample collected between the groups ( $\mathrm{IG}=\mathrm{CG}$ ), however, when analyzed separately, in the item presence of endocervical cells, the CG was higher than the IG $(p=0.0181)^{(19)}$.

\section{Discussion}

As demonstrated in this review, many barriers in relation to patients, professionals and existing systems can be overcome with well designed interventions. The selection of the interventions to be applied must take into consideration the specific characteristics of each population or service. An example of this is the evidence that economically disadvantaged women benefit more from the behavioral interventions with financial incentives, whereas women with higher incomes benefit more from the cognitive interventions(11).

Another relevant aspect to be considered in the implementation of the interventions is the site or environment. It is important to understand all the spaces of service provision as potential health promotion environments such as, for example, the hospital. Hospitalization is a valuable opportunity to discuss CUC screening, especially for indigent patients whose only contact with the health system may be the period of hospitalization. Hospitalization should be utilized as an opportunity, a moment at which people are more available to receive interventions, whether cognitive, social or behavioral. The presence of statistically significant relationships with the use of the admission form with a diagrammatic reminder(12) supports the hypothesis that the reminder intervention can improve the frequency of the documentation of screening for CUC. This suggests that the nurses were receptive to the idea of discussing prevention with the patients in the hospital and possibly just needed to be reminded.

The most direct implication of this study, performed in the hospital, is the recommendation that nurses should continue to use the reminder in their admission forms to ask about preventive health measures. However, it seems that only asking about the examination is not sufficient to promote its realization by the women, which suggests the need to also offer information on the recommended intervals, the purpose of the examination and other information (cognitive intervention), especially as this only takes a few minutes. Furthermore, depending on 
the conditions under which women are hospitalized, the opportunity should be taken to carry out the examinations in the hospital institution.

Behavioral interventions seem to have a more fleeting effect when compared to the cognitive ones. One example of this was the comparison between the telephone reminder and the telephone counseling. The first intervention initially increased adherence, but was not as effective as the telephone counseling(11). These results reiterate the need to use a combination of interventions to achieve better efficacy. Most of the interventions analyzed were cognitive, however, only four tested the effects of interactive strategies, in which the patient relates with the professional for the exchange of information. It seems that when the information is provided by the professional, with space for specific questions about the examination or even to talk about the fears and worries that surround it, there is an increase in rates of the practice of the examination when compared to only offering information in a static way (letters, pamphlets, videos etc.). This can be illustrated through the study, in which it was only possible to improve the level of knowledge of the women in relation to the colposcopy examination using an educational pamphlet, without, however, diminishing the anxiety level about the examination of the women ${ }^{(14)}$. Conversely, the studies which used telephone counseling or discussion groups to eliminate barriers (educational, psychological and practical) demonstrated a significant increase in adherence of the women to the examination(11).

To carry out more dialogued and participatory educational health activities, it is essential that the health professionals, including nurses, manage, in their professional practice, to promote the reception and to construct bonds with patients, in order to comprehend, recognize and commit themselves to meet the health needs of the patients ${ }^{(20)}$. Women who have never performed the Papanicolau examination can have difficulty adapting to the environment of traditional provision of health services. This becomes evident when there is a cultural or language difference, which requires strategies of an extensive scope ${ }^{(9)}$. In these cases social strategies are especially important, in which health counselors (trained lay people from the community), community leaders or influential people of the community can be used to carry out the intervention(21). Other social intervention strategies are the provision of specific health professionals to provide care for the determined population of women, incorporation of technologies (computer) and changes in the system. In one of the studies, the findings demonstrated a high level of satisfaction among women in both groups (examination performed by the physician and by the nurse), which could be attributed to the interpersonal skills and experience of the professional. However, the level of satisfaction among the women who carried out the examination with the nurse was statistically superior ${ }^{(19)}$. Another study also referred to an increased level of satisfaction of women who performed the examination with the nurse, citing the interpersonal skills, amicability and kindness of the nurse as the reasons ${ }^{(22-23)}$.

\section{Conclusions}

This study demonstrated that the best choice of intervention should take into consideration the characteristics of the target population, such as race, ethnicity, language, socioeconomic status, and the environment in which they will be applied (hospital, primary health unit, in the capital city, in the interior of the State).

The behavioral, cognitive and social interventions showed positive effects in the early detection of CUC, however it is suggested that, where appropriate, a combination of interventions should be used to achieve a more effective result. The low number of studies performed by nurses with evidence level equal to or greater than three was highlighted. This does not mean that nurses are not carrying out interventions, however, it reflects the fragility of the methodological designs that describe the use of these to increase the early detection of CUC. Another important fact is that among the studies found, none related to Brazilian nursing. Although all the studies were from the international literature, conducted with women of different cultures, races and ethnicities, as well as with users of a differentiated health system, all the proposed interventions are easy to reproduce and adapt to the context of Brazilian women.

It is hoped that this study encourages the nurses to conduct research on intervention using theories that support its use, as well as methodological designs with higher evidence levels, thus contributing to a consolidated and evidence-based nursing practice.

\section{References}

1. Organización Mundial de la Salud. Control integral del cáncer cervicouterino: guía de práticas esenciales. Geneva; 2007.

2. Saraiya M, Lee NC, Blackman D, Smith MJ, Morrow B, Mckenna MT. Observations from CDC. An assessement 
of Pap smears and hysterectomies among women in the United States. J Womens Health Gend Based Med. 2002;11(2):103-9.

3. U.S. Preventive Service Task Force. Screening for cervical cancer: Recommendations and rationale. Am J Nurs. 2003;103(11):101-2.

4. Rogers NM, Cantu AG. The nurse's role in the prevention of cervical cancer among underserved and minority populations. J Commun Health. 2009;34:135-43.

5. Teitelman AM, Stringer M, Averbuch T, Witkoski A. Human Papillomavirus, current vaccines, and cervical cancer prevention. J Obstet Gynecol Neonat Nurs. 2009;38:69-80.

6. Lobiondo-Wood G, Harber J. Nursing research: methods and critical appraisal for evidence-based practice. 6a ed. St. Louis (USA): Mosby/Elsevier; 2006. 7. Mendes KDS, Silveira RCCP, Galvão CM. Revisão integrativa: método de pesquisa para a incorporação de evidências na saúde e na enfermagem. Texto Contexto Enferm. 2008;17(4):758-64.

8. Ursi ES. Prevenção de lesões de pele no período perioperatório: revisão integrativa da literatura [dissertação de mestrado]. Ribeirão Preto (SP): Escola de Enfermagem de Ribeirão Preto da Universidade de São Paulo;2005.130 p.

9. Yabroff KR, Mangan P, Mandelblatt J. Effectiveness of interventions to increase Papanicolaou smear use. J Am Board Fam Med. 2003;16(3):188-203.

10. Melnyk BM, Fineout-Overholt E. Evidence-based practice in nursing \& healthcare: a guide to best practice. Philadelphia : Lippincott Williams \& Wilkins; 2005.

11. Abercrombie PD. Improving adherence to abnormal pap smear follow-up. J Obstet Gynecol Neonat Nurs. 2001;30(1):80-7.

12. Kelley CG, Daly BJ, Anthony MK, Zauszniewski JA, Stange KC. Nurse practitioners and preventive screening in the hospital. Clin Nurs Res. 2002;11(4):433-49.

13. Arevian M, Noureddine S, Kabakian-Khasholian T. Rainsing awareness and providing free screening improves cervical cancer screening among economically disadvantaged Lebanese/Armenian women. J Transcultural Nurs. 2006;17(4):357-64.

14. Tomaino-Brunner C, Freda MC, Damus K, Runowicz $C D$. Can precolposcopy education increase knowledge and decrease anxiety? J Obstet Gynecol Neonat Nurs. $1998 ; 27(6): 636-45$.

15. Paskett ED, White E, Carter WB, Chu J. Improving follow-up after an abnormal Pap smear: a randomized controlled trial. Prevent Med. 1990;19:630-41.

16. Paskett ED, Phillips K, Miller M. Improving compliance among women with abnormal Papanicolaou smears. Obstet Gynecol. 1995;86:353-59.

17. Park S, Chang S, Chung C. Effects of a cognitionemotion focused program to increase public participation in Papanicolaou smear screening. Public Health Nurs. 2005; 22(4):289-98.

18. Robson J, Boomla K, Fitzpatrick S, Jewell AJ, Taylor J, Self J, Colyer M. Using nurses for preventive activities with computer assisted follow up: a randomized controlled trial. BMJ. 1989;298:433-6.

19. Twinn S, Cheng F. Increasing uptake rates of cervical câncer screening amongst Hong Kong Chinese women: the role of the practitioner. J Adv Nurs. 2000;32(2):335-42.

20. Leonello VM, Oliveira MAC. Competências para ação educativa da enfermeira. Rev. Latino-Am. Enfermagem. 2008;16(2):177-83.

21. Giarratano G, Bustamante-Floresta R, Carter C. A multicultural and multilingual outreach program for cervical and breast cancer screening. J Obstet Gynecol Neonat Nurs. 2005;34(3):395-402.

22. Mitchell H. Pap smears collected by nurse practitioners: a comparison with smears collected by medical practitioners. Oncol Nurs Forum. 1993;20:807-10.

23. Furber SE, Donaldson C. The cost of cervical cancer screening provided by a women's health nurse. Austr J Public Health. 1992;16:226-31.
Received: Feb. $3^{\text {rd }} 2010$

Accepted: Dec. $3^{\text {rd }} 2010$ 